rev.relac.int.estrateg.segur.6(1):169-190,2011

\title{
EL DERECHO PENAL INTERNACIONAL ¿PROTECTOR DE LOS DERECHOS HUMANOS?*
}

\author{
José Fernando Botero Bernal ${ }^{* *}$
}

\section{RESUMEN}

En el presente artículo se presenta como posible y necesario el emprender la configuración de un derecho penal internacional, en tanto que saber, cuya tarea sea la de limitar el ejercicio del poder punitivo y de esa manera propenda por la vigencia real de los derechos humanos, para lo cual se han de diferenciar las nociones de poder punitivo internacional, legislación penal internacional y derecho penal de igual naturaleza, planteándose luego unas pautas generales y particulares de ese sistema de derecho penal internacional.

* El presente artículo hace parte de los resultados de la investigación terminada: "Condiciones de posibilidad para una dogmática de la parte general del derecho penal 1980-2003", que se adelantó dentro de la línea de investigación de Derecho penal del grupo de investigaciones jurídicas de la Universidad de Medellín, la cual fue financiada por la misma institución y en ella el autor participó en calidad de investigador principal.

** Abogado de la Universidad Pontificia Bolivariana (Medellín/Colombia). Docente investigador en el área de Derecho penal de la Universidad de Medellín (Medellín/Colombia). Exbecario del Deutscher Akademischer Austausch Dienst-DAAD-. Correo electrónico josefernandoboterobernal@hotmail.com o jfbotero@udem.edu.co 
Lo anterior, a fin de brindar una vigencia real de los derechos humanos, o lo que es lo mismo, el bien real y pleno de la persona.

Palabras clave: Derecho penal. Derecho penal internacional. Poder punitivo internacional. Legislación penal internacional. Dogmática penal internacional. Protección de derechos humanos.

\begin{abstract}
In this article, it is proposed as possible and necessary to undertake the configuration of an international criminal law, while knowing, whose task be to limit the exercise of punitive power, this way tending for the real validity of human rights; for it, one has to distinguish the concepts of international punitive power, international criminal legislation and criminal law of the same nature. Presenting afterwards general and specific guidelines of that system of international criminal law.The above, in order to provide a real validity of human rights, or what is the same, the real and full wellbeing of the people.
\end{abstract}

Key words: Criminal law, international criminal law, international punitive power, international criminal legislation, international criminal dogmatism, human rights protection

\title{
RESUMO
}

Neste artigo, apresenta-se como possível e necessário empreender a configuração de um direito penal internacional, cuja tarefa seja a de limitar o exercício do poder punitivo e desta maneira propenda pela vigência real dos direitos humanos, para o qual se diferenciam as noções de poder punitivo internacional, legislação penal internacional e direito penal de igual natureza, propondo a seguir umas pautas gerais e particulares deste sistema de direito penal internacional.

$\mathrm{O}$ anterior, com o fim de brindar uma vigência real dos direitos humanos, o que representa o bem real e pleno da pessoa.

Palavras chave: Direito penal. Direito penal internacional. Poder punitivo internacional. Legislação penal internacional. Dogmática penal internacional. Proteção de direitos humanos. 


\section{INTRODUCCIÓN}

Si la disciplina del derecho penal internacional generaba en la academia extranjera interés ${ }^{1}$, este aumentó desde cuando la Organización de las Naciones Unidas², en ejercicio de la potestad punitiva internacional ${ }^{3}$, el 17 de julio de 1998, "adoptó" ${ }^{4}$ lo que se conoce como el Estatuto de Roma o Estatuto de la Corte Penal Internacional ${ }^{5}$. En ese sentido son plenamente comprensibles afirmaciones, dentro de dicha disciplina, como: "La entrada en vigor del Estatuto de Roma y la institución de una Corte Penal Internacional (permanente) constituye, hasta la fecha, el último hito en la evolución del derecho penal internacional" (Werle, 2007, p. 22).

Desde entonces se han venido elaborando, por parte de la doctrina mayoritaria, discursos legitimantes del ya aludido Estatuto y con él del ejercicio del poder punitivo internacional, bien desde la pena ${ }^{6} \mathrm{o}$ desde los bienes jurídicos que supuestamente tutela ${ }^{7}$.

Otro sector, minoritario y contrario al mayoritario, viene sosteniendo que el derecho penal internacional es la manifestación de un "neopunitivimos", y en ese sentido va en contra de todos los principios que se han elaborado desde el derecho penal ${ }^{8}$.

Siendo así las cosas en la doctrina de derecho penal internacional, es perfectamente viable formular la siguiente pregunta: ¿será posible la configuración de un derecho penal internacional que no legitime al poder punitivo internacional ni a su legislación sino que limite tanto a uno como a otro?. A tal interrogante, y a manera de hipótesis, se habrá de responder que ello es posible siempre y cuando previamente se diferencien las nociones de derecho penal internacional, poder punitivo y legislación penal, ambos de igual naturaleza a aquel.

1. Ver entre otros: Jescheck (1952), Werle (2007).

2. En adelante se hará referencia a este organismo político internacional con las siglas ONU. Sobre el tema pueden verse los documentos pertinentes en http://www.un.org/spanish/law/icc/docs.htm, o directamente en: http://untreaty.un.org/ $\mathrm{cod} /$ icc/statute/finalfra.htm. donde se puede hallar el Acta final de la conferencia diplomática de plenipotenciarios de las Naciones Unidas sobre el establecimiento de una Corte Penal Internacional, la cual se celebró en la ciudad de Roma.

3. Desde este momento se ha de indicar cómo "ese poder punitivo" lo ostenta un organismo internacional que en su configuración no es nada democrático. Una cosa es que al interior de un cuerpo colegiado de naturaleza política uno o varios de sus integrantes obtengan un mayor "poder" en orden a orientar la producción de ese ente político y otra muy diferente es que se halle, por estatutos, establecido que uno de sus miembros siempre tendrá mayor "poder". Ver: ONU (1945) y Pastor (2009).

4. Ver: Werle (2007), Huet y Koering-Joulin (2005), Bassiouni (2003), Cid (2008), además los documentos pertinentes sobre la Corte Penal Internacional en: http://www.un.org/spanish/law/icc/docs.htm

5. En adelante se denotará dicho estatuto con las siglas ECPI o CPI -Corte Penal Internacional- (ICC por sus siglas en inglés).

6. Ver: Werle (2007) y Ambos (2005).

7. Ver: Machado (2010) y Sousa (2007), esta afirma: "O exercício do ius puniendi encontra a sua legitimidade na função, reconhecida ao direito criminal, de proteger subsidiariamente bens jurídicos" (Sousa, 2007, p. 6).

8. Cfr. Pastor (2006A), Pastor (2006B), Prittwitz (2003). 
Para corroborar o infirmar la antes referida hipótesis, se habrá de captar una serie de datos ${ }^{9}$ referentes al derecho penal internacional, en una serie de textos, que pueden ser calificados como de referencia, de manera crítica, esto es, se acudirá al método por excelencia dentro del saber jurídico-penal: el bibliográfico.

El presente artículo se habrá de dividir de la siguiente manera: en una primera parte se aludirá a la manera como es comprendido hoy el derecho penal internacional para luego proceder a replantear el derecho penal internacional y en una última parte establecer una serie de conclusiones.

\section{COMPRENSIÓN ACTUAL DEL DERECHO PENAL INTERNACIONAL}

\subsection{Precisiones conceptuales}

Sea lo primero aludir a la denominación y paternidad de aquella disciplina que se ocupa de la cuestión criminal internacional. No siendo ellos unívocos en la doctrina ${ }^{10}$.

En lo que hace a la paternidad, hay un sector que la atribuye al filósofo inglés Jeremy Bentham (1748-1832) ${ }^{11}$; hay otros que se la asignan a Ernst Ludwig Beling (Ernst von Beling) (1886-1932) ${ }^{12}$ e incluso hay quienes afirman que el nombre de la disciplina que se ocupa de la cuestión criminal internacional fue utilizada (ya) "en el año de 1888 en la obra del internacionalista boliviano Santiago Vaca Guzmán (1847-1896)" (Jiménez de Asúa, 1997, p. 721)³.

No obstante no haber unanimidad en torno a quién es el padre de la locución, sí hay entre quienes se les ha asignado ese status, por lo menos, dos puntos en común: de un lado, aludieron a la legislación sin diferenciarla del "poder" que la generaba; y de otro lado, el concepto de derecho penal internacional comprendía, esencialmente, problemas de validez de la ley penal en el espacio ${ }^{14}$; en fin, esta disciplina en sus inicios era concebida como "...la face internationale du droit pénal" (Donnedieu de Vabres, 1992, p. 6).

En lo que atañe a la denominación, ella ha generado no pocas controversias entre quienes se han referido al tema; se habla, por citar las denominaciones más defendidas, de

9. Ver: Botero (2003)

10. Cfr. Gil (1999), Andrés (2006), Quintano (1955), Ambos (2000), Werle (2007), Jiménez de Asúa (1992) y Fierro (1997).

11. Ver: Donnedieu de Vabres (1922).

12. Cfr. Jescheck y Weigend (1996), siguiendo a este autor se halla Ambos (2000), Werle (2007) y todos se basan en: Beling (1896) y Jiménez de Asúa (1997).

13. Las fechas son ajenas al texto original.

14. Parece verlo así, ampliándolo a la "cooperación judicial" y a la "Corte Penal Internacional" Fletcher (2007). 
"Derecho Internacional Penal"15 o de "Derecho Penal Internacional" (Völkerstrafrecht) ${ }^{16}$; también se acude a la locución "Internationales Strafrecht"17.

Sin querer desconocer la distinción que se hace, por un muy buen sector de la doctrina ${ }^{18}$, entre "derecho penal internacional" y "derecho internacional penal", se considera que, dada esa particularidad que le es propia a la legislación que conforma esta disciplina, es decir, tener como consecuencia jurídica una pena, entiéndase privativa de la libertad, la denominación a utilizarse habrá de ser "derecho penal internacional" o, con otras palabras, esta disciplina contiene una serie de normas que, si bien son formalmente de naturaleza internacional ${ }^{19}$, su nota predominante es la que en su interior contemplan, para determinadas conductas, una pena, y ella es el objeto de estudio del derecho penal. Con lo expresado en precedencia no se niega el carácter internacional de la legislación (característica formal), sino que se resalta la característica material de dicha legislación que contiene, como consecuencia jurídica, una pena privativa de la libertad, como regla general.

Es menester señalar que la denominación "derecho penal internacional" no quiere significar la imposición de un saber (el penal) sobre otro (el internacional público), sino que responde, como ya se anotara, al sustrato material de la normatividad que la recoge, valga decir, una pena ${ }^{20}$.

Ahora bien, las instituciones penales, que cierta parte de la doctrina ${ }^{21}$ ubica bajo la noción de "derecho penal internacional", por ejemplo, la extradición, la extraterritorialidad de la ley penal nacional, entre otros, realmente no son otra cosa que legislaciones penales nacionales con vocación internacional o , si se quiere, instituciones penales nacionales con vocación internacional.

Antes de proseguir se considera necesario hacer tres anotaciones a título de colofón del presente punto: (i) la primera, en relación con el tema en precedencia, si se acoge la locución alemana "Völkerstrafrecht", esta se halla compuesta por dos palabras, a saber: Völker, plural de Volk, que significa pueblo, nación; y por la palabra Strafrecht, que traduce Derecho Penal, por lo que en sentido estricto su significado debería ser Derecho Penal de los Pueblos o Naciones ${ }^{22}$.

15. Ver: Quintano (1955), Zaffaroni, Alagia y Slokar (2000) y Cassese (2005). Para su momento una buena recapitulación sobre el tema se puede consultar a Jiménez de Asúa (1992).

16. Ver: Jescheck (1952), Ambos (2000) y Werle (2007). Aunque esa locución ha sido traducida también como Derecho internacional penal, Cfr. Jescheck y Weigend (1996), Wessels y Beulke (2008), Neubacher (2005), Graf (2007). Por su parte Huet y Koering-Joulien (2005) hablan de "Droit pénal international".

17. Cfr. Dahm, Delbrück y Wolfrum (2002) y Satzger (2010), quien alude a la locución "Internationales Strafrecht" indicando que tiene varios significados y habla de "Völkerstrafrecht" -derecho penal internacional-, "Supranacionales Strafrecht" -Derecho Penal supranacional-, "Rechtshilferecht" -Normas o Derecho de cooperación- y "Strafanwendungsrecht" -derecho de aplicación (ejecución) penal-.

18. Ver: Mantovani (2009) y Glaser (1954).

19. Al parecer con otro pensamiento: Satzger (2008).

20. Ver en este sentido a Werle (2007).

21. Ver los autores mencionados en la nota núm. 15.

22. Ver: Velásquez (2009). Lo anterior, no quiere decir que exista un "ius cogens penal"; siguiéndose así a Pastor (2006A). 
(ii) La segunda, es claro la doble naturaleza de las normas sobre las cuales se ha de construir la disciplina a la que se viene haciendo alusión; de un lado, son internacionales atendiendo los órganos de producción, y de otro, son penales en cuanto hace a su contenido, esto es, son formalmente internacionales y materialmente penales ${ }^{23}$. Con razón se afirma que una norma, para que haga parte de la legislación penal internacional, exige tres características:

... en primer lugar, la norma debe describir un injusto imputable individualmente y amenazar con una pena como efecto jurídico; en segundo lugar, la norma debe ser parte del ordenamiento jurídico internacional; y en tercer lugar, la punibilidad debe existir con independencia de la recepción del tipo delictivo en el orden jurídico estatal (Werle, 2007, p. 36).

Incluso una norma internacional, no obstante no cumpla con todas las anteriores exigencias, podrá hacer parte de la legislación penal siempre y cuando cumpla, por lo menos, con alguna de estas exigencias: (i) o bien complemente alguna de las normas que cumplen todos los requisitos indicados en el texto citado, así entonces podrían ser normas penales internacionales, por ejemplo, y sin querer agotar el tema, los convenios de Ginebra (Artículo 8 Num. 2, Estatuto de la Corte Penal Internacional, en adelante ECPI), (ii) o bien, contenga principios aplicables al derecho penal internacional (Art. 21 Num. 1 Lit. B).

En fin, son normas de derecho penal internacional (legislación penal internacional) no solo aquellas que prohíben conductas señalando una pena, como se podría entender desde posturas imperativistas, sino que también son normas de igual naturaleza todas aquellas que bien contemplen principios de interpretación del derecho penal internacional o bien complementen las ya existentes.

(iii) Y la tercera: la disputa sobre la denominación que debe recibir la disciplina que se ocupa de la cuestión penal internacional no es tan importante como la de diferenciar el poder punitivo internacional (internationale Strafgewalt) del derecho penal internacional (Völkerstrafrecht), para evitar caer en neopunitivismos como los que se viven actualmente.

\subsection{Precisiones conceptuales: Poder punitivo internacional, legislación penal internacio- nal y derecho penal internacional}

Al analizar la doctrina del derecho penal internacional se observa cómo ella ${ }^{24}$, cuando se refiere al derecho penal internacional, o bien lo concibe como un complejo normativo que, de un lado,

23. Ver opinión similar en Heine y Vest (2008), Dahm, Delbrück y Wolfrum (2002). Desde una perspectiva tradicional Cfr. Ascensio, Decaux y Pellet (2000).

24. Ver, por ser autores de referencia: Werle (2007), Ambos (2000) y Cassese (2008). 
establece un catálogo de crímenes internacionales y, de otro, crea una pena para ese catálogo, es decir, como "las normas que fundamentan una punibilidad de forma directa en el derecho internacional" (Werle, 2007, p. 35) 25; o lo entienden en términos de persecución y sanción de los autores de los "crímenes graves que constituyen una amenaza para la paz, la seguridad y el bienestar de la humanidad" (Valencia, 2003, p. 11-12).

Por lo tanto, es necesario deslindar el poder punitivo internacional (internationale Strafgewalt), la legislación penal internacional (internationales Strafgesetz) y el derecho penal internacional (Völkerstrafrecht) -saber del derecho penal internacional (Wissen des Völkerstrafrechts)-. Solo realizando tal deslinde se podrá plantear la posibilidad de configurar un derecho penal internacional que limite el ejercicio de un poder punitivo internacional.

El poder punitivo internacional, en tanto que poder, no difiere estructuralmente del local; en ese sentido aquel, como expresión del modelo punitivo para abordar los conflictos sociales, es un dato fáctico que, conforme con las ciencias sociales, es de suyo violento ${ }^{26}$, en tanto que su instrumento principal es la pena, en especial la privativa de la libertad, y selectivo ${ }^{27}$, puesto que no se ejerce frente a todos los conflictos sociales, previamente denominados así, ni frente a todos los autores de esos conflictos sino frente a quienes presentan, en relación con el poder punitivo, un mayor grado de desprotección ${ }^{28}$. Así mismo, el poder en referencia acude a la "ideología de la punición infinita" (Pastor, 2009, p. 213), para lograr el control y la disciplina de quienes integran la sociedad global.

Así entonces, derecho penal internacional no puede ser violencia; de hecho, si no se excluye al poder punitivo ${ }^{29}$ internacional de aquel, sería fácil entender a este como una nueva expresión únicamente punitiva ${ }^{30}$, es decir, verlo como un elemento bélico más, y parece ser esta la postura mayoritaria. Para decirse de una vez, es innegable la gravedad de los conflictos sociales revestidos con los nombres de "crímenes de lesa humanidad", (Art. 5 y Art. 7 CPI) "genocidio" (Art. 5 y Art. 6 ECPI) y "crímenes de guerra" (Art. 5 y Art. 8 EPCI), pero ello no puede conducir, per se, a ver en el poder punitivo internacional la única forma de abordarlos y mucho menos la de habilitar su ejercicio con simples controles formales y unos escasos controles materiales.

25. Ver también a Ambos (2000).

26. Ver Muñoz (1999).

27. Ver a Baratta (2004). Con referencia al derecho penal internacional consultar a Zolo (2007).

28. Entre mayor sea ese grado de desprotección frente al poder punitivo, mayores serán las posibilidades de ser "criminalizado" por este. Un ejemplo, para efectos del presente tema, puede ser el caso del señor Omar Hasan Ahmad Al-Bashir, actual presidente de Sudan, quien tiene dos órdenes de arresto por parte de la Corte Penal Internacional, las cuales no ha sido posible llevarlas a cabo. Cfr. Corte Penal Internacional (2009) y Corte Penal Internacional (2010).

29. Ver Baratta (2004).

30. Cfr. cómo se plantea ello al Derecho penal Internacional en Ascensio, Decaux y Pellet (2000) y Cassese (2008). 
Por lo tanto, el derecho penal internacional debe liberarse de la idea práctica y violenta que le dio vida, esto es, la de sancionar; ya desde $1474^{31}$ dicha idea se dejaba ver con suma claridad tanto en el proceso de Nürnberg, cuyo Tribunal Militar Internacional se le asignó la tarea de "enjuiciar y condenar a los principales criminales de guerra del Eje Europeo"32 (Tribunal Militar Internacional de Nürnberg 33 , 1945, p. 2), como en el proceso de Tokio a cargo del Tribunal Militar Internacional para el lejano Oriente ${ }^{34}$.

Tampoco el derecho penal internacional puede ser confundido con la legislación de esa misma naturaleza; si bien aquel, en tanto que saber, se ocupa de la interpretación, esta no puede ser reducida a un conjunto de reglas de derecho.

Entender al derecho penal internacional como reglas de derecho mediante las cuales se individualizan una serie de conductas y se les amenaza con una pena, conduce no solo a confundir el objeto de interpretación ${ }^{35}$-la legislación- con su resultado y sistematización sino también a presentar a la disciplina en mención como expresión de un simple punitivismo y por esa vía se legitimaría el poder punitivo internacional.

En ese sentido, esta disciplina (saber) no puede ser comprendida ni como violencia, poder punitivo, ni como un "body international rules" (Cassese, 2008, p. 3) sino como aquel discurso, si se quiere saber, cuya funcionalidad es la de limitar el poder punitivo para logar, poco a poco, el bien pleno y real de la persona real o, lo que es lo mismo, la vigencia real de los derechos humanos.

\subsection{La situación colombiana en relación con la distinción entre poder punitivo, legislación y derecho penal internacional}

De manera concreta, en el medio jurídico penal colombiano el derecho penal internacional (Völkerstrafrecht) no ha sido totalmente ajeno, al menos nominalmente; de hecho, se pueden distinguir varias posturas con relación a dicha disciplina: comenzando desde quienes negaban su existencia ${ }^{36}$, pasando por quienes la consideraron un saber naciente, o por lo menos un saber sobre el cual "algo se ha adelantado" (Romero, 1969, p. 19), o quienes la identificaban con el derecho penal nacional con repercusiones internacionales o simplemente la tratan a la par

31. Cfr. Bassiouni (2005) y Creppi (1999).

32. El resalto ajeno al texto original.

33. Se alude al estatuto que rigió lo conocido como proceso de Nürnberg, texto que se adoptó el 6 de octubre de 1945.

34. Ver un breve extracto en WERLE (2007).

35. Cfr. Amati, Caccamo, Costi, Fronza y Vallini (2006).

36. Ver: Reyes (1984), cuya postura, para su momento, era válida bajo la condición de comprender, erróneamente, derecho penal y Ley penal. Así mismo, Mesa (1962). 
con este ${ }^{37}$, tal vez siguiendo la ubicación utilizada por algunos autores extranjeros al tratar esta disciplina ${ }^{38}$, Ilegando hasta quienes ya le confieren pleno reconocimiento ${ }^{39}$. Dejando de lado los problemas de ubicación o incluso de equiparación, se puede afirmar, de cara a las posturas que aceptan la existencia de un derecho penal internacional, lo siguiente: (i) Primero, cuando aluden a la legislación penal internacional (internationales Strafgesetz) pareciera ser que la equiparan con el saber del derecho penal internacional (Wissen des Völkerstrafrechts). (ii) Segundo, en la mayoría de los textos de derecho penal general patrio acogen la tradicional distinción entre derecho penal internacional y derecho internacional penal ${ }^{40}$, entendiendo por aquel ese conjunto de normas internas de carácter penal con vocación a tener aplicación en el extranjero y otras, de carácter internacional, relativas a la asistencia y cooperación en la persecución penal; y por este, la normativa internacional en la cual se individualiza, al menos en teoría, una serie de conductas y se les conmina con una pena; y (iii) Tercero, desde hace unos años se vienen adelantado estudios específicos en el ámbito del Derecho Penal internacional ${ }^{41}$, pero aún, no obstante haberse realizado contados intentos ${ }^{42}$, falta un texto de Derecho Penal Internacional que, sin abandonar los puntos comunes en la literatura especializada, de un lado, encare la problemática que presenta el Estado colombiano y, de otro, que permita un diálogo con el discurso jurídico penal vigente, en orden a que por vía del derecho penal comparado se configure un saber de derecho penal internacional que tenga como centro a la persona real, claro está que enmarcada dentro de un contexto social.

Con esta concreta mención histórica se busca corroborar la idea de que, según la doctrina colombiana, al igual que la doctrina extranjera, pareciera que se está dejando de lado la distinción entre poder punitivo internacional (internationale strafgewalt), legislación o ley penal internacional (internationales Strafgesetz) y derecho penal internacional (Völkerstrafrecht) o, más exactamente, saber del Derecho Penal internacional (Wissen des Völkerstrafrechts).

37. Ver: Gaitán (1963), Barrientos (1977) y Pérez (1967) quien presentó, para el momento en el cual escribió la primera edición de su obra, un adecuado resumen del derecho penal internacional, manteniendo esa postura en las ediciones siguientes de su tratado (1975 y 1984).

38. Cfr., por su influjo en la literatura especializada vernácula, entre otros a: Liszt (1914), Mezger (1985), Jiménez de Asúa (1992), también a Jescheck y Weigend (1996).

39. Ver, entre otros muchos, a Fernández (1986), Velásquez (2009).

40. Cfr. Azuero (2008), quien presenta contenidos similares a los de la doctrina mayoritaria colombiana, pero cambiando las denominaciones, es decir, Ilamando Derecho Penal Internacional a lo que la plurimencionada postura mayoritaria titula Derecho Internacional Penal, y Derecho Internacional Penal a lo que la ya mencionada postura mayoritaria llama Derecho Penal Internacional.

41. Sin querer demeritar algún estudio, se debe aludir al trabajo que sobre el particular se viene haciendo desde el Grupo Latinoamericano de Estudios sobre el Derecho Penal Internacional; sus publicaciones en: www.department-ambos.unigoettingen.de/index.php/es/Forschung/lateinamerikanische-studiengruppe-zum-internationalen-strafrecht.html (última visita: 4 de abril de 2011).

42. Ver: entre otros, Camargo (2004), Saavedra y Gordillo (1996A), Saavedra y Gordillo (1996B), Guerrero (2003), Ibáñez (2003) y Fonseca (2004). 
Lo mencionado en precedencia no solo es propio de Colombia sino que es común a la mayoría de países de Sur y Centro América ${ }^{43}$.

\section{PAUTAS PARA LA CONFIGURACIÓN DE UN SABER PENAL INTERNACIONAL}

\subsection{Pautas Generales}

Una vez deslindado el derecho penal internacional del poder punitivo, por un lado, y de la legislación de igual naturaleza, por otro, se puede ya entrar a ver qué se comprende por ese primer concepto, ello es, derecho penal internacional.

Si lo que se debe entender por derecho penal internacional ya no puede ser confundido ni con esa capacidad de sancionar (poder punitivo internacional) ni con las normas internacionales, las cuales tienen como nota característica el tener como consecuencia jurídica una pena, a no otro punto se llega, desde una perspectiva liberal, sino al de ver este derecho como un saber con un muy determinado objeto de estudio (legislación penal de naturaleza internacional) y funcionalidad (intención), la de limitar el ejercicio del poder punitivo.

Así entonces, ya se puede decir que derecho penal internacional es esa disciplina que brinda una serie de elementos normativos para efectos de limitar el ejercicio del poder punitivo internacional o, para decirse en forma mucho más clara, es un saber normativo que, mediante la interpretación de la legislación penal (Zaffaroni, Alagia y Slokar, 2000, p. 5) internacional, configura un sistema ${ }^{44}$ que limita el ejercicio del poder punitivo en orden a propender por la dignidad de la persona real y en ese sentido de la comunidad para inclinarse por la vigencia real de los derechos humanos ${ }^{45}$.

Aunque no sea el objeto central del escrito, es posible afirmar que el fundamento filosófico que debe orientar la configuración de ese sistema de compresión del derecho penal internacional debe ser un realismo personalista, sin que ello equivalga a prescindir de la sociedad, puesto que la persona real es su dimensión de alteridad; ese "llegar a ser con otros en el mundo" (Lucas, 1996, p. 174), supone a la comunidad (sociedad).

43. Cfr. Por ejemplo, Donna (2008), en donde, pareciera ser, se plantea una asimilación entre poder punitivo internacional y derecho penal internacional. Cury (2005), Dotti (2004), Villavicencio (2006) y Hurtado (2005).

44. La utilización de la palabra "sistema" no supone, de manera obligatoria, que el saber del derecho penal internacional se incline por un modelo europeo continental (que tiene su referente en el sistema alemán). Tanto el saber del derecho penal europeo continental como el modelo del "common law" son sistémicos, en el sentido kantiano, de unidad de conocimientos bajo una misma idea; en lo que se diferencian es en cómo organizan esos conocimientos. Para decirse de una manera más sencilla, lo que diferencia a ambos sistemas no es el "qué" sino el "cómo".

45. Ver: Zaffaroni, Alagia y Slokar (2000), que ofrecen una definición de derecho penal, la cual se sigue en el presente escrito. 
Ese saber del derecho penal internacional tiene unas muy claras características: (i) Primera: se halla fundado sobre una política criminal de los derechos humanos ${ }^{46}$. (ii) Segunda: debe elaborar un sistema práctico y practicable, en la medida en que debe brindar a sus aplicadores (la judicatura penal internacional) una serie de elementos normativos, deducidos de la ley penal internacional, para materializar la intencionalidad propia del saber en estudio, la cual no es otra que la de limitar el poder punitivo.

Ahora las elaboraciones normativas (construcciones dogmáticas) que brinde el saber en mención deben estar al alcance no solo del funcionario judicial internacional sino también del nacional, en orden a que este, en los casos "locales" concretos y sometidos a su conocimiento, pueda, para fundamentar sus decisiones, recurrir a ellas; no se niega el problema de compatibilidad entre los textos legales internacionales, que sirvieron de base para las elaboraciones científicas normativas, y los textos nacionales, pero dicha problemática deberá ser vista en cada caso concreto. Por esta vía entonces aparece una función que, al menos para el Sur y Centro de América, tiene una vital importancia: el derecho penal internacional como un limitante al ejercicio del poder punitivo nacional y de esta forma el ejercicio de ese poder se verá contenido no solo desde el derecho penal de cada país sino desde el ya mencionado derecho penal internacional.

Se debe reiterar que, si bien el ejercicio del poder punitivo internacional y la legislación penal igualmente internacional son subsidiarios (\$10 del Preámbulo y Artículo 1 ECPI -principio de complementariedad-), las elaboraciones del saber penal internacional ya no necesariamente deben ser subsidiarias en tanto que deben ayudar a la judicatura nacional.

Esto último, para complementar lo ya acotado, cobra gran importancia para la administración de justicia, por ejemplo, de los Estados de América Latina, en donde las elaboraciones dogmáticas deben ser "reforzadas" o, si se quiere, completadas, puesto que ellas se construyen sobre legislaciones (regla de derecho) creadas por un poder político influenciado, de manera significativa, por la presión de grupos ilegales (Captura del Estado), es decir, aquí la labor del derecho penal internacional, entendido como un saber acotante del poder punitivo, es la de apoyo a la administración de justicia.

Dicha labor de apoyo será mucho más fácil si, como ocurre, por ejemplo, en Colombia (Art. 135 ss. del Código Penal47), Perú (Art. 319 CP), Bolivia (Art. 138 CP), Ecuador (Ley 1 de 2009), Chile (Ley 20357), Panamá (arts. 431, 432, 433 CP) y Uruguay (arts. 1 y 23 de la Ley 18.026), la normativa penal nacional describe una serie de conductas para cuya interpretación es perfectamente válido el saber del derecho penal internacional.

46. Cfr. Botero (2005).

47. Se utilizará la abreviatura CP para significar Código Penal. 
Y (iii) Tercera: tiene una clara y expresa funcionalidad (intencionalidad), como es la de limitar el ejercicio del poder punitivo.

El plurimencionado saber del derecho penal internacional implica la elaboración de un programa racional de comprensión activa de la legislación penal internacional ${ }^{48}$, y con ello se está diciendo que no se debe renunciar a la tarea de construir un sistema que, desde la interpretación de la ley penal internacional (ECPI, entre otros textos legales internacionales) y principios generales de igual naturaleza ${ }^{49}$, otorgue una serie de criterios de imputación que limiten el ya tantas veces mencionado poder punitivo.

En este punto, el saber al cual se viene aludiendo no puede dejarse orientar por posturas metodológicas que se presentan como las más adecuadas para ciencias caracterizadas por multiplicidad de posiciones. Se hace así referencia a lo que se conoce como tópica o pensamiento problemático ${ }^{50}$. Tal postura tiene sus orígenes en Aristóteles (384 a.C. - 322 a.C.), Marco Tulio Cicerón (106 a.C. - 43 a.C.) y Giovanni Battista Vico (1668-1744), aunque posiblemente por la mayéutica pueda ubicarse también a Platón. Dicha corriente fue presentada, a mediados del siglo pasado (1950/1953), por Theodor Viehweg (1907-1988), y buscaba cambiar el método sistemático por un "argumentar en pro y acerca de todas y cada una de las posibles soluciones buscando llegar a un consenso" (Zaffaroni, Alagia y Slokar, 2000, p. 375). -Plantear el caso concreto e ir brindándole todas las posibles soluciones, hasta llegar a una en la cual hubiera pleno consenso: las soluciones en función del caso y en donde prima aquella que logre un consenso-. Esta forma de abordar una determinada situación conflictiva, como ya fuere expuesto ${ }^{51}$, no es propio del modelo penal donde las relaciones no son horizontales sino verticales, de autoridad -lo cual se reproduce perfectamente en el ámbito internacional-; así mismo, el consenso en torno a una respuesta no quiere decir que ella sea la correcta; igualmente, si con la tópica lo que se quiere es llamar la atención al intérprete para que esté dispuesto a aceptar otras posibles respuestas que no sean las suyas, no es necesario sacrificar la idea de configurar un sistema, solo se debe pensar en la respuesta más adecuada conforme al sistema.

Este programa -sistema- debe tener una determinada funcionalidad. Ella tiene la re-legitimación del poder punitivo y en ese sentido no sería necesario deslindar poder punitivo internacional, legislación y derecho de iguales naturalezas o, por el contrario, la de limitar ese poder porque, por un lado, él es estructuralmente violento y selectivo y, por otro, solo así se puede

48. Ver el trabajo que sobre el particular se viene realizando por Ambos (2000), Ambos (2008), Ambos (2010), Olásolo (2010) y Mateus (2008).

49. Cfr. una breve e ilustrativa mención en Scabas (1999).

50. Ver una adecuada presentación de la misma, que no se aborda aquí por motivos del objeto central y de espacio, en: Viehweg (1974), Atienza (2005); explicando su funcionamiento Gimbernat (1999).

51. Ver. Zaffaroni, Alagia y Slokar (2000) y Gimbernat (1999). 
lograr el bien de la persona real ${ }^{52}$, lo que se traduce en la vigencia real de los derechos humanos; postura esta que es la que se viene argumentado en el presente escrito.

Haciendo referencia a las generalidades de ese sistema, sin abordar las particularidades que del mismo se deben derivar y las que se hallaren condicionadas, en lo que a su configuración respecta, por la funcionalidad del saber al cual pertenecen, se puede aseverar que actualmente se viene abogando por "una teoría del delito "funcional de derecho comparado" (Ambos, 2005B, p. 20. $)^{53}$, es decir, seguir los lineamientos del funcionalismo moderado -Derecho penal orientado a las valoraciones político-criminales ${ }^{54}-\mathrm{o}$, más exactamente, "dejar penetrar las decisiones valorativas político-criminales en el sistema del Derecho penal" (Roxin, 1973, p. 10).

Tal opción supone, de un lado, la negación de datos ónticos previos y obligantes para quien configura -intérprete- $y$, de otro, unas bases neokantianas (idealistas) ${ }^{55}$; bases estas que facilitan la elaboración de elementos (componentes) normativos para brindar respuestas que no sean contrarias a la política criminal.

Una propuesta en ese sentido y de cara a la funcionalidad limitante que debe poseer el saber del derecho penal internacional merece ciertas aclaraciones: Primera: es cierto que el sistema que se adopte por parte del saber en estudio debe estar dotado de elemento normativos, pero igualmente cierto es, que dicho sistema, emanado del saber del derecho penal internacional, así como sus elementos particulares, no puede estar desligado totalmente de la realidad, para evitar la construcción normativa - deber ser-que, por estar tan alejada del ser, nunca tendrá la mínima oportunidad de poder regular la realidad; en ese sentido cualquier configuración que se intente deberá tener a la realidad como limitante. Segunda: se debe estar muy atento a lo que se entiende por política criminal, toda vez que ese concepto, que por cierto es equívoco, puede significar poder punitivo; con otras palabras, si cuando en el contexto al cual se alude se habla de política criminal para expresar esa capacidad de perseguir de manera eficiente una serie de situaciones conflictivas calificadas como crímenes internacionales (Art. 5 al 8 ECPI), se estaría haciendo referencia expresa, a no otra cosa, sino al poder punitivo, y en ese sentido ya el saber del derecho penal internacional no estaría orientado a limitar a aquel sino a legitimarlo. En consecuencia, no se puede admitir un sistema que se halla orientado por la política criminal internacional, entendida como se expresara en precedencia.

52. Cfr. Zaffaroni (2009), quien utiliza otras palabras.

53. Cfr. Ambos (2000).

54. Ver: Silva (1992) y Roxin (2000). Lo que se busca con la teoría funcionalista moderada es brindar un sistema abierto para resolver las contradicciones entre respuestas dogmáticamente correctas y políticamente satisfactorias, relacionando de manera inescindible la política criminal y la dogmática penal. Tarea esta que ya desde los años 50 venía haciendo Thomas Würtenberger en Würtenberger (1965) y Roxin (2006).

55. Cfr. Como lo afirma expresamente quien ha sido calificado el padre del funcionalismo moderado: Roxin (2006). 
Así entonces, el sistema de comprensión activo del derecho penal internacional, (i) primero, ha de basarse en elementos normativos; (ii) segundo, estos elementos normativos, tanto genéricos como específicos, habrán de tener a la realidad como una limitante y, (iii) tercero, los susodichos componentes deben ser configurados de una manera tal que no habiliten siempre y de cualquier manera el ejercicio del poder punitivo; en este punto se puede presentar un problema: en principio las situaciones que le atañen al saber del derecho penal internacional expresan un grado enorme de injusto (Zaffaroni, 2009, p. 126) que difícilmente se podría pensar en la no imposición de pena ${ }^{56}$; como respuesta a ellos, en ese orden de ideas, fácil es aseverar que los elementos -criterios de imputación-que posibiliten llegar a su imposición deberán estar configurados con arreglo a ese fin. Sin negar la gravedad de las situaciones que serán y han sido puestas a consideración del saber penal internacional, ellas no pueden conducir a afirmar, siempre y en todo momento, la habilitación de una pena puesto que, de un lado, tal proceder le haría perder los límites éticos al saber al cual se viene haciendo referencia, y de otro, la pena, de cara a unos hechos que relevan un enorme grado de injusto, deberá tener unos límites en cuanto hace, por lo menos, a la cantidad de pena y esto ya supone cierto grado de contención.

Pero debe reconocerse que el problema del saber del derecho penal internacional se halla más, que en el método a seguir para la construcción de ese programa racional, en los intereses políticos de quienes generan la legislación penal internacional; es en esta disciplina donde se nota con mayor claridad la tensión entre los intereses políticos y la racionalidad del sistema de comprensión de la ley penal internacional.

De cara a la finalidad propia del saber en mención, la opción que tiene el interprete es no por los intereses del poder punitivo sino por la racionalidad del sistema y, solo así, se podrá configurar un saber que efectivamente limite y no se convierta en un legitimador de ese poder punitivo internacional.

Lo antes expresado es también una negativa a aceptar posturas intermedias o conciliadoras en el sentido de aceptar, en algunas ocasiones, ciertos intereses provenientes de los creadores de la legislación penal internacional en la construcción de ese sistema. Asumir esa actitud es restarle carácter limitativo a ese programa racional que supone el sistema.

Lo indicado en precedencia, no es óbice para, por vía del derecho comparado, entrar en diálogo con el derecho foráneo buscando, como se ha dicho ya, "la aceptación universal de una Parte General del Derecho Penal Internacional" (Ambos, 2008, p. 72), incluso aquella actitud es una obligación por cuanto así lo exige el método del derecho penal comparado y a la cual se llega por dos vías: una supralegal, que viene dada por la esencia misma del saber penal internacional, la que es de naturaleza supranacional, y otra de carácter normativa, establecida por la remisio-

56. Cfr. Zaffaroni (2009). 
nes que hace el ECPI a principios o parámetros que suponen el estudio de legislación foránea, entre otros ejemplos, cuando se alude a los principios generales del derecho penal (art. $22 \mathrm{ECPI}$ ), el derecho aplicable por la Corte Penal Internacional (art. 21, 1, c) ECPI), los elementos normativos que integran la noción de "crimen", el esquema procesal que se halla implementado en el ECPI.

\subsection{Pautas particulares}

Sin pretender desarrollar en su totalidad el tema, por espacio y tema, es menester aludir a pautas particulares para la configuración de los criterios de imputación, sin perder de vista que ellos, por un lado, deben estar orientados por funcionalidad del saber penal internacional: limitar al poder punitivo de igual naturaleza y, de otro, que "las reglas de imputación (del derecho penal internacional) siguen estando subdesarrolladas" (Ambos, 2008, p. 69) ${ }^{57}$.

La tendencia actual es la de presentar un sistema y, por lo tanto, unos criterios de imputación que se acercan al adoptado por el common law, ello es, la división, por un lado, entre actus reus/mens rea (offences) y, por el otro, de "defences" (Art. 31, Art. 32 y Art. 33 ECPI) o supuestos excluyentes de responsabilidad; tal postura responde a consideraciones normativas, es decir, a una supuesta tendencia que presenta el articulado del ECPI hacia el sistema propia del common law ${ }^{58}$.

Sin embargo, se considera que tal postura no es tan acertada como se podría creer, por lo menos, por dos razones: (i) la primera: ninguna legislación penal, sea ella internacional o nacional, se afilia a un determinado sistema; la construcción de este se halla en manos de la doctrina; este, el sistema, se construye con base en aquella, la legislación, pero no por imposición; por algo, cuando se estaba discutiendo el articulado de lo que es hoy el ECPI, se trató de evitar locuciones que condujeran inexorablemente a afirmar que dicho cuerpo normativo optaba por un determinado sistema ${ }^{59}$ y, (ii) la segunda: el mismo articulado permite la construcción de un sistema europeo continental de influjo germánico ${ }^{60}$, obviamente con una funcionalidad diferente a la establecida por el influjo alemán, esto es, la de limitar y no la de legitimar el poder punitivo.

Solo para esbozar algunas ideas sobre esos criterios de imputación que deben emerger del sistema del derecho penal internacional, se puede indicar lo siguiente: en atención a no pocos artículos del ECPI, entre los cuales se pueden mencionar los arts. 6, 7 y 8 ECPI, se puede cons-

57. Ver sobre ello a: Hirsch (2006) y Fletcher (2007).

58. Cfr. por ejemplo, Fletcher (2007).

59. Ver: Werle (2007).

60. Ver: Ambos (2008), Bueno y Zaragosa (2003). 
truir el elemento normativo conducta, el cual si bien es jurídico no puede ser contrario a como se da en la realidad, por ello esa conducta estará regida por una intencionalidad. Continuando, con base en los ya citados artículos unidos a los arts. 30, 25, $31 \mathrm{ECPI}$, se puede construir el estrato normativo de la tipicidad; luego, con fundamento en el preámbulo, así como los artículos que tienen como contendido material una conducta punible (Art. 6, Art. 7 y Art. 8 ECPI) y algunos supuestos del Art. $31 \mathrm{ECPI}$, es posible el configurar la antijuridicidad, y de esta manera se halla configurado el injusto, tanto en sus componentes positivos como negativos, para posteriormente pasar al componente normativo limitante de la culpabilidad (responsabilidad), el cual encuentra su fundamento legal en los arts. 23, 31 d), 33 c) del ECPI.

Obviamente, cada uno de estos elementos normativos requieren ser construidos, en lo que hace a sus especificidades, teniendo en cuenta la finalidad propia del derecho penal internacional: limitar el ejercicio del poder punitivo, no solo internacional sino también nacional.

En fin, se debe reiterar que las pautas particulares sobre un criterio de imputación limitador son un inicio que requiere un ulterior desarrollo. En ese desarrollo estará el futuro de un derecho penal internacional que no se ha identificado con el poder punitivo (pena), de un derecho penal internacional que no sea una teoría de la violencia (pena) sino un limitador de ella.

\section{CONCLUSIONES}

Llegados a este punto, bien puede expresarse que si de lo que se trata con el derecho penal internacional es propender por la vigencia de los derechos esenciales de las personas, ello supone no otra cosa que la de limitar el poder punitivo internacional y tal tarea solo se logra mediante la configuración de un saber penal internacional cuya funcionalidad, manifiesta y latente, sea esa, o con otras palabras, es perfectamente viable el plantear al tantas veces referido derecho penal internacional como un derecho de contención de ese dato fáctico denominado poder internacional y de esta manera generar un espacio en el cual solo rijan los derechos esenciales del ser humano; espacio aquel que gradualmente aumentará en la medida en que efectivamente se limite el ejercicio del poder al que se viene haciendo referencia.

Lo anterior, como fuera en reglones precedentes desarrollado, implica en un primer momento escindir las nociones de poder punitivo internacional, legislación penal internacional -ECPI entre otros instrumentos internacionales- $y$ derecho penal de igual naturaleza, a fin de sustraer de este la violencia y selectividad que le es inherente al poder punitivo, o con otras palabras, lo llamado a ser limitado por sus características es este poder y su limitador debe provenir del derecho, del derecho penal internacional. Para cumplir con la finalidad antes señalada, se debe configurar al interior del derecho penal internacional un sistema de comprensión activa de la legislación internacional, del cual emerjan unos criterios de imputación, cuya funcionalidad vendrá dada por la asignada a aquel sistema de comprensión activa, es decir, la limitación del 
poder punitivo a fin de generar un espacio, antes zona de la violencia y selectividad del plurimencionado poder punitivo, que podrá ser ocupado por la vigencia de los derechos esenciales de la persona -derechos humanos-.

Sólo así, se reitera, se podrá pensar en un discurso jurídico penal internacional que, al limitar el ejercicio del poder punitivo de idéntica naturaleza, brinde una vigencia real y plena a los derechos humanos, es decir, un derecho penal internacional que, en palabras de la postura mayoritaria, proteja los derechos humanos.

\section{BIBLIOGRAFÍA}

- Amati, E., Caccamo, V., Costi, M., Fronza, E. \& Vallini, A. (2006). Introduzione al Diritto penale internazionale. Milano: Giuffré.

- Ambos, K. (2000). Der Allgemeine Teil des Völkerstrafrechts: Ansätze einer Dogmatisierung. Berlin: Duncker und Humblot.

- $\quad$ Ambos, K. (2005A). Estudios de derecho penal internacional. Caracas: Universidad Católica Andrés Bello.

- Ambos, K. (2005B). La construcción de una parte General del Derecho Penal Internacional. En K. Ambos, E. Malarino, \& J. Woischnik. Temas actuales de Derecho Penal Internacional. (13-40). Montevideo: KonradAdenaeur-Stiftunge E.V.

- Ambos, K. (2008). ¿Cómo imputar a los superiores crímenes de los subordinados en el Derecho Penal Internacional? Fundamentos y formas. Bogotá: Externado de Colombia.

- Ambos, K. (2010). El Derecho Penal Internacional en la encrucijada: de la imposición ad hoc a un sistema universal basado en un tratado internacional. En Política criminal, Vol. 5, No. 9, 237-256. Disponible en: http://www.politicacriminal.cl/Vol_05/n_09/Vol5N9A6.pdf.

- Andrés, A. C. (2006). Derecho Penal Internacional. Valencia: Tirant lo Blanch.

- Ascensio, H., Decaux, E. \& Pellet, A. (2000). Droit International Pénal. Paris: Pedona.

- Atienza, M. (2005). Las Razones del Derecho. Teoría de la argumentación jurídica. (1a. Ed.). México: Universidad Autónoma de México, Instituto de Investigaciones Jurídicas.

- Azuero, J. C., (2008). Diferencias entre el Derecho Penal Internacional y el Derecho Internacional Penal. Prolegómenos-Derechos y Valores, Vol. XI, 22,. 181-217.

- Baratta, A. (2004). Derechos Humanos: entre violencia estructural y violencia penal. En A. Baratta Criminología y sistema penal. Compilación in memoriam. (334-356). Montevideo: B de f. 
- Barrientos, S. (1977). Elementos de Derecho Penal. (3a. Ed.). Medellín: Colección Jurídica Bedout.

- $\quad$ Bassiouni, M. Ch. (2003). Introduction to International Criminal Law. New York: Transnational Publishers.

- Bassiouni, M. Ch. (2005). The Legislative of the International Criminal Court: Introduction, Analysis, and Integrated Text. (Vol. I). New York: Transnational Publishers.

- Beling, E. (1896). Die Strafrechtliche Bedeutung der Exterritorialität. Beiträge zum Völkerrecht und zum Strafrecht. Breslau: Franck \& Weigert.

- Botero, A. (2003). La metodología en la investigación jurídica: Alcances y perspectivas. Opinión jurídica, Vol. 4, No. 4, 109-116.

- Botero, J. F. (2005). Lineamientos de una política criminal de los derechos humanos. Desde una postura personalista realista. Opinión jurídica, Vol. 4, No. 7, 67-85.

- $\quad$ Bueno, F. \& Zaragosa, J. de M. (2003). Manual de Derecho Penal Internacional. Madrid: Comillas.

- Camargo, P. P. (2004). Manual de Derecho Penal Internacional. Partes General, Especial y Procedimental ante la Corte Penal Internacional. Bogotá: Leyer.

- $\quad$ Cassese, A. (2005). Lineamenti di diritto internazionale. I. Dirrito sostanziale. Bologna: Mulino.

- Cassese, A. (2008). International Criminal Law. (2a. Ed.). New York: Oxford.

- Cid, M.I. (2008). La Corte Penal Internacional. Un largo camino. Madrid: Dykinson.

- Corte Penal Internacional. (2009). Caso The Prosecutor v. Omar Hasan Ahmad Al-Bashir ICC-02/05-01/ 09. Extraído abril 4, 2011, desde: http://www.icc-cpi.int/Menus/ICC/Situations+and+Cases/Situations/ Situation+ICC+0205/Related+Cases/ICC02050109/Court+Records/Chambers/PTCl/1 .htm .

- Corte Penal Internacional. (2010). Caso The Prosecutor v. Omar Hasan Ahmad Al-Bashir ICC-02/05-01/ 09. Extraído abril 4, 2011, desde: http://www.icc-cpi.int/menus/icc/situations\%20and\%20cases/situations/ situation\%20icc\%200205/related\%20cases/icc02050109/court\%20records/chambers/ptci/95?lan=en-GB.

- Creppi, E. (1999). La evolución de la responsabilidad penal individual bajo el derecho internacional. International Review of the Red Cross, 835, pp. 531-554 Disponible en: http://www.icrc.org/web/spa/ sitespa0.nsf/html/5TDNNF.

- Cury, E. (2005). Derecho Penal. Parte General. (7a. Ed.). Santiago de Chile: Universidad Católica de Chile.

- Dahm, G., Delbrück, J. \& Wolfrum, R. (2002). Völkerrecht. (Tomo I/3.) (2a. Ed.). Berlin: De Gruyter Recht. 
- Donna, E. A. (2008). Derecho Penal. Parte General. Fundamentos-Teoría de la ley penal. (Tomo I). (1a. Ed.). Buenos Aires: Rubinza-Culzoni.

- Donnedieu de Vabres, H. (1992). Introduction a l'etude du droit pénal international. Paris: Librairie de la socété du Recueil Sirey.

- Dotti, R. A. (2004). Curso de Direito Penal: Parte Geral. (2a. Ed.). Río de Janeiro: Forense.

- Fernández, J. (1986). Derecho penal fundamental. (Vol. I). (2a. Ed.). Bogotá: Temis.

- Fierro, G. J. (1997). La ley penal y el Derecho Penal Internacional. (2a. Ed.). Buenos Aires: Tipografía Editora Argentina.

- Fletcher, G. P. (2007). The Grammar of Criminal Law. American, Comparative, and International. (Volumen One). New York: Foundations Oxford.

- Fonseca, C. M. (2004). Elementos y delimitación de los crímenes internacionales. Bogotá: Nueva Jurídica.

- Gaitan, B. (1963). Curso de Derecho Penal. Parte General. Bogotá: Lerner.

- Gil, A. (1999). Derecho Penal Internacional. Madrid: Tecnos.

- Gimbernat, E. (1999). Concepto y método de la ciencia del derecho penal. Madrid: Tecnos.

- Glaser, S. (1954). Introduction a l’etude du Droit International Pénal. Bruxelles: Établissements Émile Bruylant.

- Graf, W. (2007). Völkerrecht. (4a. Ed.). Berlin: De Gruyter Rechtwissenschaften.

- Guerrero, O. J. (2003). Corte Penal Internacional. Comentarios a la sentencia C-578 de 2002 de la Corte Constitucional. Bogotá: Legis.

- Heine, G. \& Vest, H. (2008). Völkerstrafrecht. FS 2008. Alemania: Universität Bern.

- Hirsch, H. J. (2006) Internalización del Derecho Penal y de la Ciencia del Derecho Penal. Ciencia del Derecho Penal nacional y universal. Revista Penal, No. 17, pp. 166-176.

- Huet, A. \& Koering-Joulin, R. (2005). Droit pénal international. Paris: Presses Universitaries de France.

- Hurtado, J. (2005). Manual de Derecho Penal. Parte General (I.). (3a. Ed.). Lima: Grijley.

- Ibáñez, A. J. (2003). El sistema penal en el estatuto de Roma. Bogotá: Universidad Externado de Colombia. 
- Jescheck, Hans-Heinrich \& Weigend, T. (1996). Lehrbuch des Strafrechts. Allgemeiner Teil. (5a. Ed.). Berlin: Duncker \& Humblot.

- Jescheck, Hans-Heinrich. (1952). Die Verantwortlichkeit der Staatsorgane nach Völkerstrafrecht. Eine Studie zu den Nürnberger Prozessen. Bonn: Ludwing Röhrscheid.

- Jiménez de Asúa, L. (1992). Tratado de Derecho Penal. (Tomo II). (5a. Ed.). Buenos Aires: Losada.

- Jiménez de Asúa, L. (1997). Principios de Derecho Penal. La ley y el Delito. (3ạa. Ed.) Bueno Aires: Abeledo Perrot.

- $\quad$ Liszt, F. v. (1914). Lehrbuch des Deutschen Strafrecht. Berlin: J. Guttentag.

- Lucas, J. de S. (1996). Las dimensiones del hombre. Antropología filosófica. Salamanca: Sígueme.

- Machado, F. M. (2010). El Derecho internacional penal: sistema del delito y claves en el futuro en el Estatuto de Roma. Sistema Penal \& Violência, Volumen 2, No. 1. Disponible en: http:// revistaseletronicas.pucrs.br/ojs/index.php/sistemapenaleviolencia.

- Mantovani, F. (2009). Diritto Penale. Parte Generale. (6ª . Ed.). Padova: CEDAM.

- Mateus, J. P. (2008). La transformación de la teoría del delito en el Derecho Penal Internacional. Barcelona: Atelier.

- Mesa, L. E. (1962). Lecciones de Derecho Penal. Parte General. Medellín: Universidad de Antioquia.

- Mezger, E. (1985). Derecho Penal. Parte General. México: Cárdenas, editor y distribuidor.

- Muñoz, F. (1999). Derecho Penal y control social. (2ª Ed.). Bogotá: Temis.

- Neubacher, F. (2005). Kriminologisch Grundlagen einer internationalen Strafgerichtsbarkeit. Tübingen: Mohr Siebeck.

- Olásolo, H. (2010). Estudios de Derecho Penal Internacional. México: Instituto Nacional de Ciencias Penales.

- ONU. (1945). Carta de las Naciones Unidas. Extraído abril 4, 2011, desde: http://www.un.org/es/documents/ charter/intro.shtml el 4 de abril de 2011.

- Pastor, D. (2006). El Derecho Penal del Enemigo en el espejo del poder punitivo internacional. En M. Cancio \& C. Gómez-Jara (Coord). Derecho Penal del Enemigo. El discurso penal de la exclusión. Vol. 2, (pp. 475-522). Buenos Aires: Euro Editores. 
- Pastor, D. (2006). La deriva neopunitivista de organismos y activistas como causa del desprestigio actual de los derechos humanos. En Jura Gentium, 1, 1-38, Disponible en: http://www.juragentium.unifi.it/es/ surveys/latina/pastor.htm.

- Pastor, D. (2009). Encrucijadas del Derecho Penal Internacional y del Derecho Internacional de los Derechos Humanos. Bogotá: Pontificia Universidad Javeriana.

- Pérez, L. C. (1967). Tratado de Derecho Penal. (Tomo I). Bogotá: Temis.

- $\quad$ Prittwitz, C. (2003). Internationales Strafrecht: Die Zukunft einer Illusion?. En B. Sharon, J. Hruschka \& J. C. Joerden (Coord), Jahrbuch für Recht und Ethik. (T. 11) (pp. 469-488). Berlin: Duncker \& Humblot.

- Quintano, A. (1955). Tratado de Derecho Penal Internacional e Internacional Penal. (Tomo I). Madrid: Consejo Superior de Investigaciones Científicas.

- $\quad$ Reyes, A. (1984). Tratado de Derecho Penal. (9a. Ed.). Bogotá: Universidad Externado de Colombia.

- $\quad$ Romero, L. E. (1969). Derecho Penal. (Volumen I). Bogotá: Temis.

- $\quad$ Roxin, C. (1973). Kriminalpolitik und Strafrechtssystem. (2a. Ed.). Berlin: Walter de Gruyter.

- Roxin, C. (2000). La evolución de la política criminal, el Derecho penal y el Proceso penal. Valencia: Tirant lo Blanch.

- $\quad$ Roxin, C. (2006). Strafrecht. Allgemeiner Teil. Band I. Grundlagen, Der aufbaue der Verbrechenslehre. (4a. Ed.). München: C.H. Beck.

- Saavedra, E. \& Gordillo, C. (1996). Derecho Penal Internacional. (Tomo I). Bogotá: Ibáñez.

- Saavedra, E. \& Gordillo, C. (1996). Derecho Penal Internacional. (Tomo II). Bogotá: Ibáñez.

- Satzger, H. (2008). La internacionalización del Derecho Penal como reto para el principio de principio de determinación penal. Revista Penal, No. 21, 139-147.

- Satzger, H. (2010). Internationales und Europäisches Strafrecht. (4a. Ed.). Baden-Baden: Nomos.

- Scabas, W. A. (1999). Principios generales del Derecho Penal. En K. Ambos \& O.J. Guerrero. El Estatuto de Roma de la Corte Penal Internacional. (pp. 271-314). Bogotá: Temis.

- Silva, Jesús-María. (1992). Aproximaciones al Derecho Penal Contemporáneo. Barcelona: Bosch.

- Sousa, S. A. (2007). Sobre o bem jurídico-penal protegido nos crimes contra a humanidades. Societe Internacionale de Defense sociale pour une politique criminelle Humaniste. XV Congreso Internacional de defensa social. Disponible en: http://www.defensesociale.org/xvcongreso/cfp_es.php 
- Tribunal Militar Internacional de Nürnberg. (1945). Estatuto del Tribunal Militar Internacional de Nürnberg. Extraído 4 abril, 2011, desde: http://www.ehu.es/ceinik/tratados/7TRATADOSRELATIVOSACRIMENESDEGUERRA/ CG73.pdf

- Valencia, A. (2003). Compilación de Derecho Penal Internacional. El Estatuto de Roma y otros instrumentos de la Corte Penal Internacional. Bogotá: Oficina del alto comisionado de la Naciones Unidas para los Derechos Humanos.

- Velásquez, F. (2009). Derecho Penal. Parte General. (4a. Ed.). Medellín: Comlibros.

- Viehweg, T. (1974). Topik und Jurisprudenz. Ein Beitrag zur rechtswissenschaftlichen Grundlagenforschung. (5a. Ed.). München: Beck.

- Villavicencio, F. (2006). Derecho Penal. Parte General. Lima: Grijley.

- Werle, G. (2007). Völkstrafrecht. (2a. Ed.). Berlin: Mohr Siebeck.

- Wessels, J. \& Beulke, W. (2008). Strafrecht Allgemeiner Teil. Die Straftat und ihr Aufbau. (38a. Ed.). Heidelberg: C.F. Müller Verlag.

- Würtenberger, T. (1965). La situazione spirituale della scienza penalistica in Germania. Milano: Giuffré.

- Zaffaroni, E. R. (2009). Hacia dónde va el poder punitivo. Medellín: Sello Editorial Universidad de Medellín.

- Zaffaroni, E. R., Alagia, A. \& Slokar, A. (2000). Derecho Penal. Parte General. Buenos Aires: Ediar.

- Zolo, D. (2007). La justicia de los vencedores. De Nuremberg a Bagdad. Madrid: Trotta. 